\title{
Takotsubo cardiomyopathy in the course of Hashimoto's disease - a description of two cases
}

\author{
Kardiomiopatia takotsubo w przebiegu choroby Hashimoto - opis dwóch \\ przypadków
}

\author{
Małgorzata Zalewska-Adamiec¹, Hanna Bachórzewska-Gajewska², Anna Tomaszuk-Kazberuk³, \\ Jolanta Małyszko ${ }^{4}$, Sławomir Dobrzycki ${ }^{1}$
}

\author{
${ }^{1}$ Department of Invasive Cardiology, Medical University in Bialystok, Poland \\ Head of the Department: Prof. Sławomir Dobrzycki MD, PhD \\ ${ }^{2}$ Department of Clinical Medicine, Medical University in Bialystok, Poland \\ Head of the Department: Prof. Hanna Bachórzewska-Gajewska MD, PhD \\ ${ }^{3}$ Department of Cardiology, Medical University in Bialystok, Poland \\ Head of the Department: Prof. Bożena Sobkowicz MD, PhD \\ ${ }^{4}$ Department of Nephrology, Dialysis and Internal Medicine, Warsaw Medical University, Poland \\ Head of the Department: Prof. Jolanta Małyszko MD, PhD
}

Takotsubo cardiomyopathy (TTC), is also called "apical ballooning syndrome" and "stress cardiomyopathy". It is a clinical condition in which there are transient contractility disturbances of the apex of the left ventricle (LV) and ischaemic changes on electrocardiography (ECG) with no significant changes in coronary arteries. The clinical course of TTC is similar to the course of acute coronary syndromes. The main symptom is usually chest pain, in laboratory tests increased concentration of cardiac necrotic markers is observed, and on ECG ischaemic changes are recorded $[1,2]$.

Takotsubo cardiomyopathy was described for the first time by Sato et al. [3] in Japan in 1990. The name of the syndrome comes from a boat with a narrow upper part and broad bottom used for catching octopus. Such vessels resemble the shape of the LV that is seen on ventriculography in patients with "apical ballooning syndrome" [4].

In recent years it was observed that younger females with TTC relatively often suffer from thyroid diseases [5]. We would like to present two cases of female patients with TTC and Hashimoto's disease.

A 44-year-old woman, who did not report a history of cardiac diseases or any significant cardio-vascular risk factors, was referred from the District Hospital to the University Hospital due to severe chest pain and tachycardia. The patient was treated with levothyroxine due to hormonal hypothyroidism for many years and had lost about $20 \mathrm{~kg}$ of weight during the preceding year.

On admission the patient was stable, without chest pain, and on ECG sinus tachycardia 120/min and ST-segment elevation in I, II, III, aVF, V3-V6 leads, QT interval - $414 \mathrm{~ms}$ were recorded (Figure 1). In laborato- ry tests (with serum) raised concentration of troponin I and raised levels of inflammation parameters were observed (leukocyte count 10,700/ $\mu \mathrm{l}, \mathrm{CRP}-42.6 \mathrm{mg} / \mathrm{l}$ ) (Table 1). The patient underwent urgent coronary angiography, which did not reveal any significant atherosclerotic changes (Figure 2). An echocardiography scan revealed hypokinesis of the apex and apical and middle segments of anterior and lateral walls with ejection fraction (EF) assessed as 50\%.

During further hospitalisation the patient was in a stable condition. The chest pains did not recur, and a gradual decrease of cardiac necrotic markers was observed. On ECG evolution of ischaemic changes was recorded - on the fourth day negative $\mathrm{T}$ waves in $\mathrm{I}$, II, aVL, and aVF leads and deep negative $\mathrm{T}$ waves in V3-V6 leads with QTc - 497 ms were seen (Figure 3). The patient was diagnosed with TTC.

In further laboratory tests abnormal lipid profile, reduced thyroid-stimulating hormone (TSH) concentration, and increased concentration of fT3 (triiodothyronine) and fT4 (thyroxine) were observed (Table 1). The patient was consulted by an endocrinologist. Ultrasound scan of the thyroid revealed normal dimension of the thyroid with homogeneous structure, but with decreased echogenicity and normal vascularisation (image resembling Hashimoto's disease), and focal pathological findings with normal echogenicity with a diameter of about $5 \mathrm{~mm}$ in the inferior part of the left lobe (Figure 4). The patient was diagnosed with Hashimoto's disease. Triiodothyronine was withdrawn due to subclinical hyperthyroidism. An antithyroid drug was not given.

The patient was treated with acetylsalicylic acid (ASA), enoxaparin, bisoprolol, ramipril, simvastatin, 


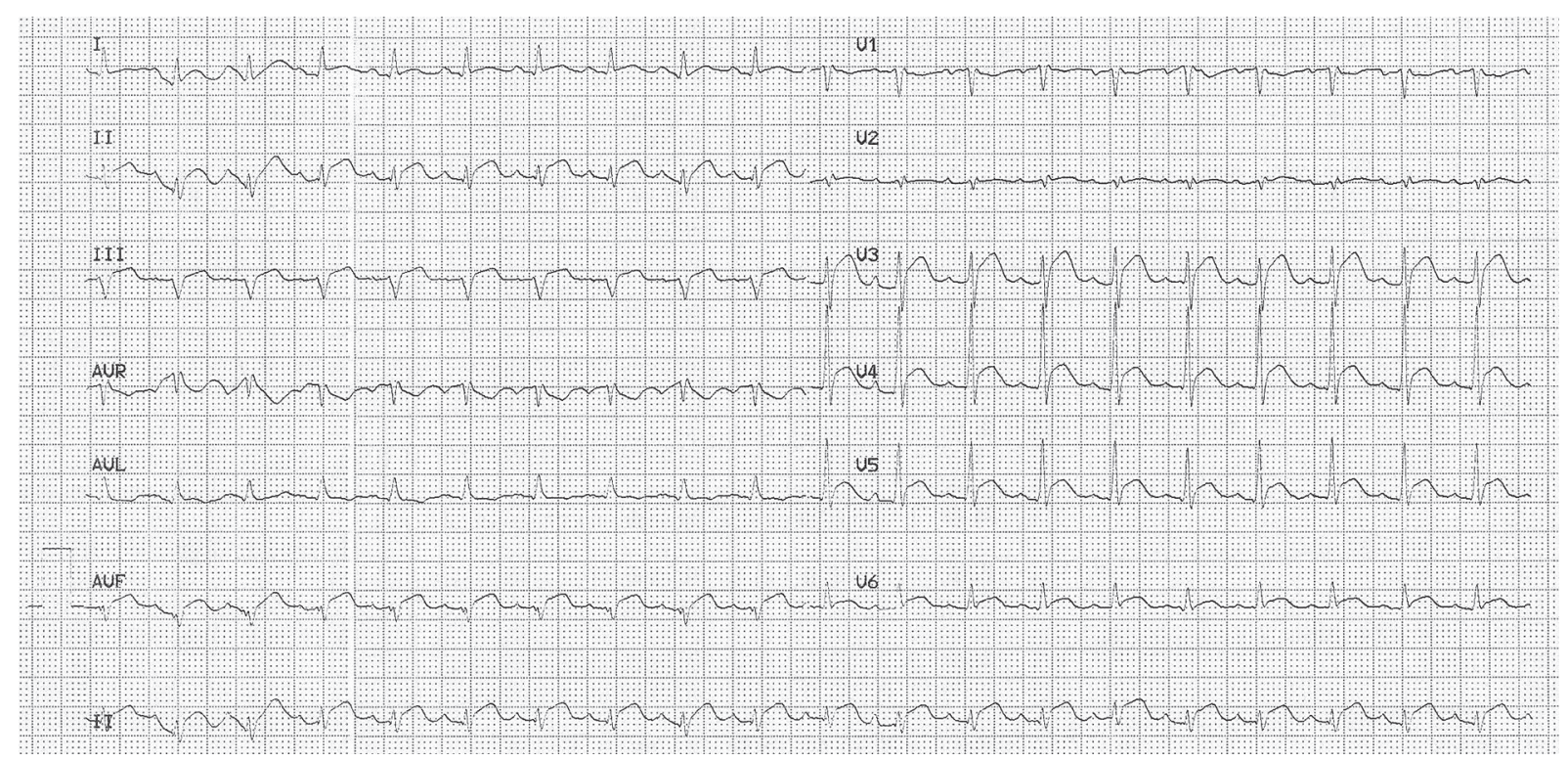

Figure 1. ECG recording on admission, $25 \mathrm{~mm} / \mathrm{s}$ (patient 1) - description in the text

Table 1. Laboratory parameters of both patients.

\begin{tabular}{|c|c|c|c|c|}
\hline \multirow[t]{2}{*}{ Parameter } & \multicolumn{2}{|c|}{ Patient 1} & \multicolumn{2}{|c|}{ Patient 2} \\
\hline & Value & Normal range & Value & Normal range \\
\hline Troponin I [ng/ml] & 10.915 & $0.00-0.30$ & 3.04 & $<0.20$ \\
\hline CK $[U / l]$ & 320 & $25-170$ & - & - \\
\hline CK-MB [U/I] & 71 & $0-26$ & 27 & $<24$ \\
\hline Total cholesterol [mg/dl] & 105 & $130-200$ & 301 & $<200$ \\
\hline LDL cholesterol [mg/dl] & 67 & $130-160$ & 225 & $<135$ \\
\hline HDL cholesterol [mg/dl] & 27,2 & $45-65$ & 43 & $>65$ \\
\hline Triglycerides [mg/dl] & 54 & $40-200$ & 167 & $<200$ \\
\hline $\mathrm{TSH}[\mu \mathrm{IU} / \mathrm{ml}]$ & 0.1558 & $0.350-4.940$ & 55.100 & $0.400-4.000$ \\
\hline fT3 [pg/ml] & 6.41 & $1.71-3.71$ & 1.79 & $1.80-4.20$ \\
\hline fT4 [ng/dl] & 2.73 & $0.70-1.48$ & 0.36 & $0.89-1.76$ \\
\hline Anti-TG [IU/ml] & - & - & $<20.0$ & $0-40$ \\
\hline Anti-TPO [IU/ml] & - & - & $>1000$ & $0-35$ \\
\hline
\end{tabular}

$C K$ - creatine kinase, CK-MB - cardiac fraction of creatine kinase, LDL cholesterol - low-density lipoprotein, HDL cholesterol - high-density lipoprotein, TSH - thyroid-stimulating hormone, fT3 - triiodothyronine, fT4 - thyroxine, Anti-TG - anti-thyroglobulin, Anti-TPO - anti-thyroid peroxidase.

and omeprazole and was discharged home with the recommendation of regular drug taking, echocardiography control after 3 months, and visits to cardiac and endocrinology out-patient departments.

A 58-year-old female patient, who did not report any history of cardiac diseases or any significant cardio-vascular risk factors, with long-lasting retrosternal chest pain at rest and with strong suspicion of acute coronary syndrome was transferred to the University Hospital from the Casualty and Emergency
Department of the District Hospital for further diagnostics and treatment.

On admission the patient was stable with blood pressure 187/112 $\mathrm{mm} \mathrm{Hg}$ and heart rate 80/min. On investigation we did not find abnormalities apart from obesity (body mass index (BMI) $-32 \mathrm{~kg} / \mathrm{m}^{2}$ ). On ECG sinus rhythm $80 / \mathrm{min}$ and negative T waves in I, II, aVL, and V2-V6 leads were recorded (Figure 5).

The patient underwent coronary angiography, which revealed coronary arteries without atheroscle- 

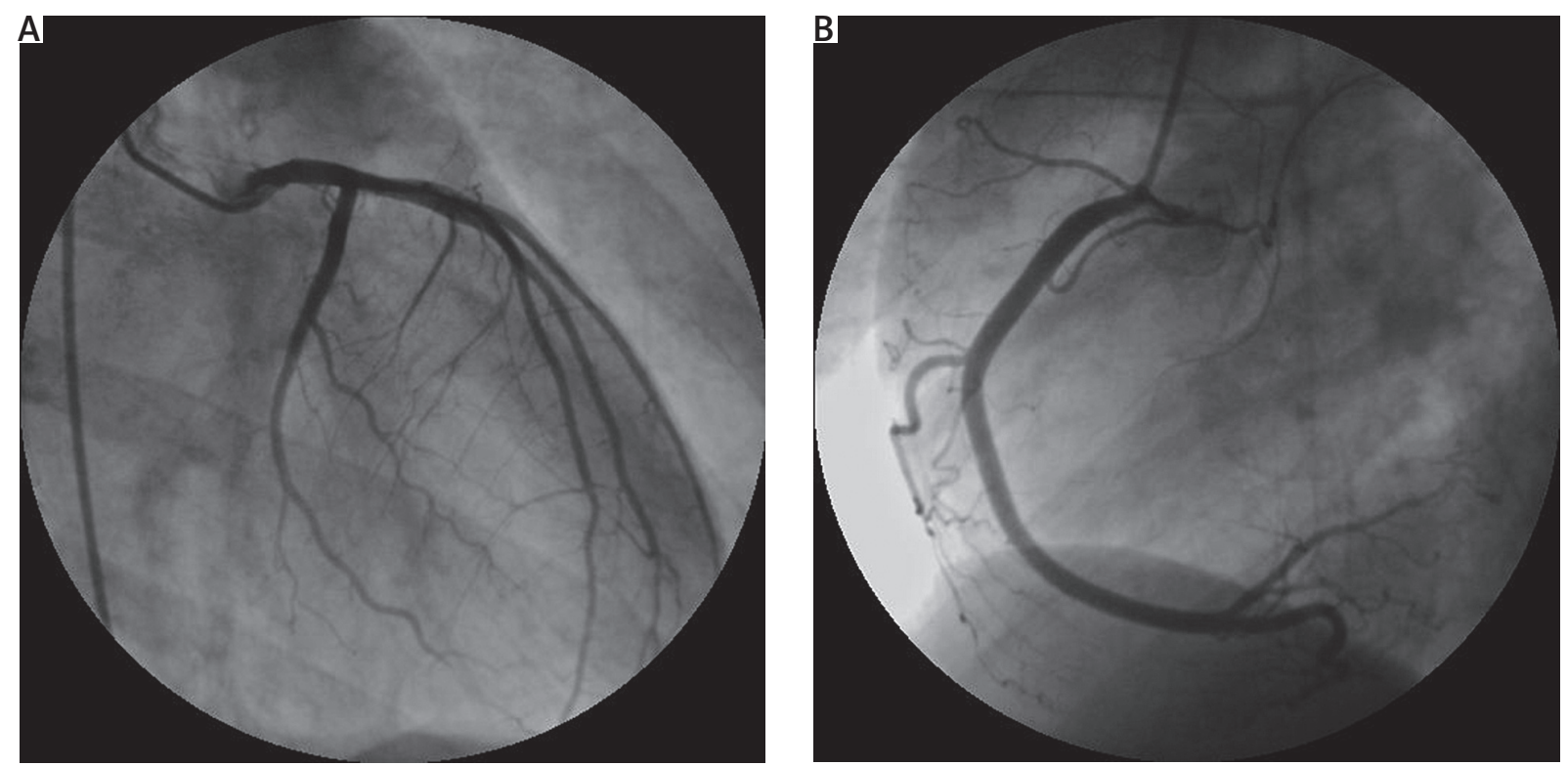

Figure 2. Coronary angiogram of the left coronary artery and the right coronary artery (patient 1) - coronary arteries without atherosclerotic lesions

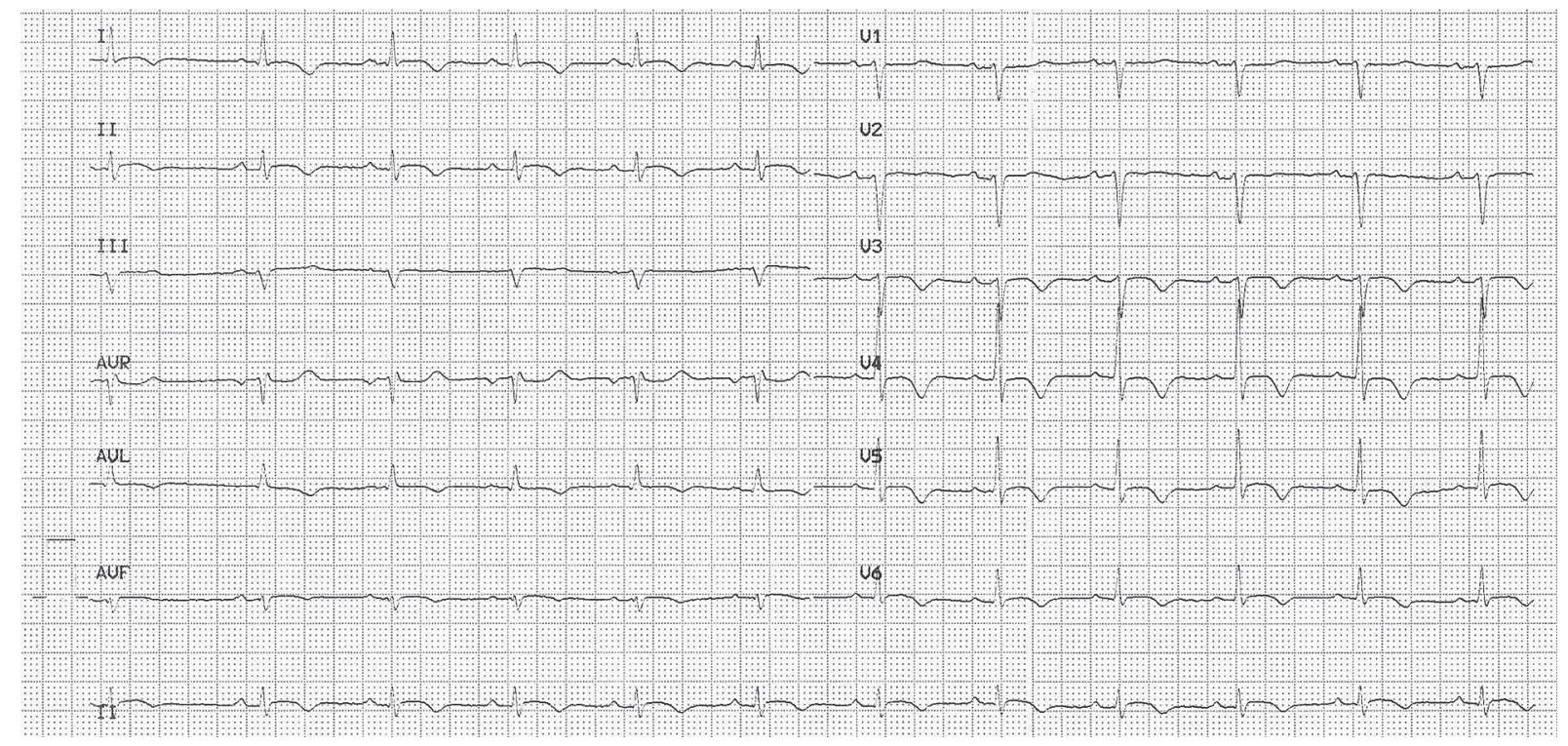

Figure 3. ECG recording on fourth day, $25 \mathrm{~mm} / \mathrm{s}$ (patient 1) - description in the text

rosis. On ventriculography contractility disturbances in the apex and apical segments of the left ventricle typical for TTC were observed. In laboratory tests a slightly elevated concentration of troponin I was found (Table 1). An echocardiography scan showed hypokinesis of the apex and antero-septal wall of the LV with EF 45\%.

In further laboratory tests significantly abnormal lipid profile, very high TSH concentration, and decreased concentrations of fT3 and fT4 were observed (Table 1). An ultrasound scan of the thyroid revealed normal dimensions of the thyroid with decreased echogenicity and granular heterogeneous structure (image resembling thyroiditis). Thyroid antibody tests revealed normal concentration of anti-TG (anti-thyroglobulin) and elevated concentration of anti-thyroid peroxidase (anti-TPO) (Table 1). The patient was consulted by an endocrinologist and was diagnosed with Hashimoto's disease with hypothyroidism. Treatment with levothyroxine was started. The patient was scheduled for a visit to see an endocrinologist in the out-patient department. 

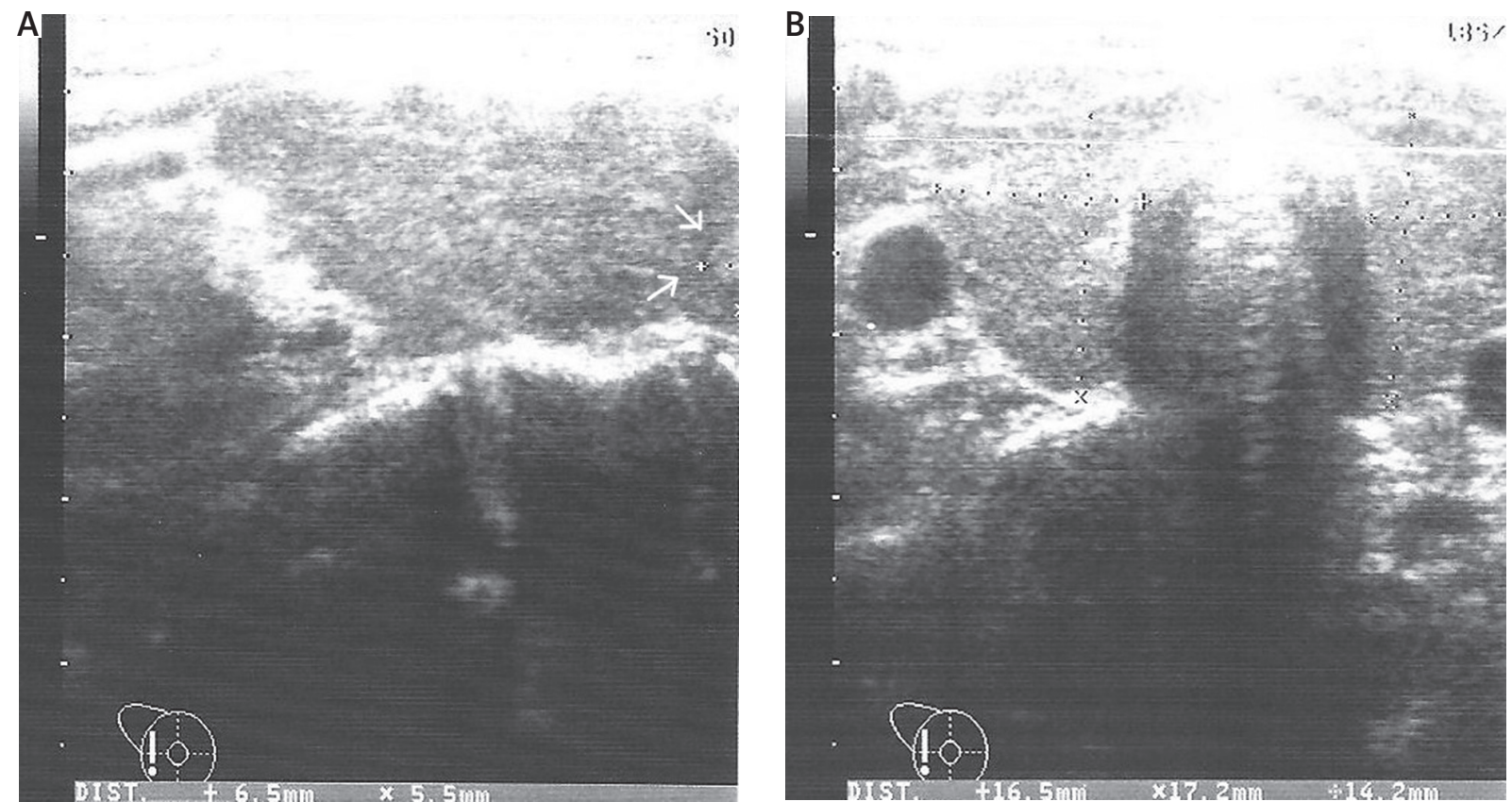

Figure 4. Ultrasound scan of the thyroid (patient 1) - the white arrows indicate the focal pathological finding with normal echogenicity with diameter about $5 \mathrm{~mm}$; remaining description in the text
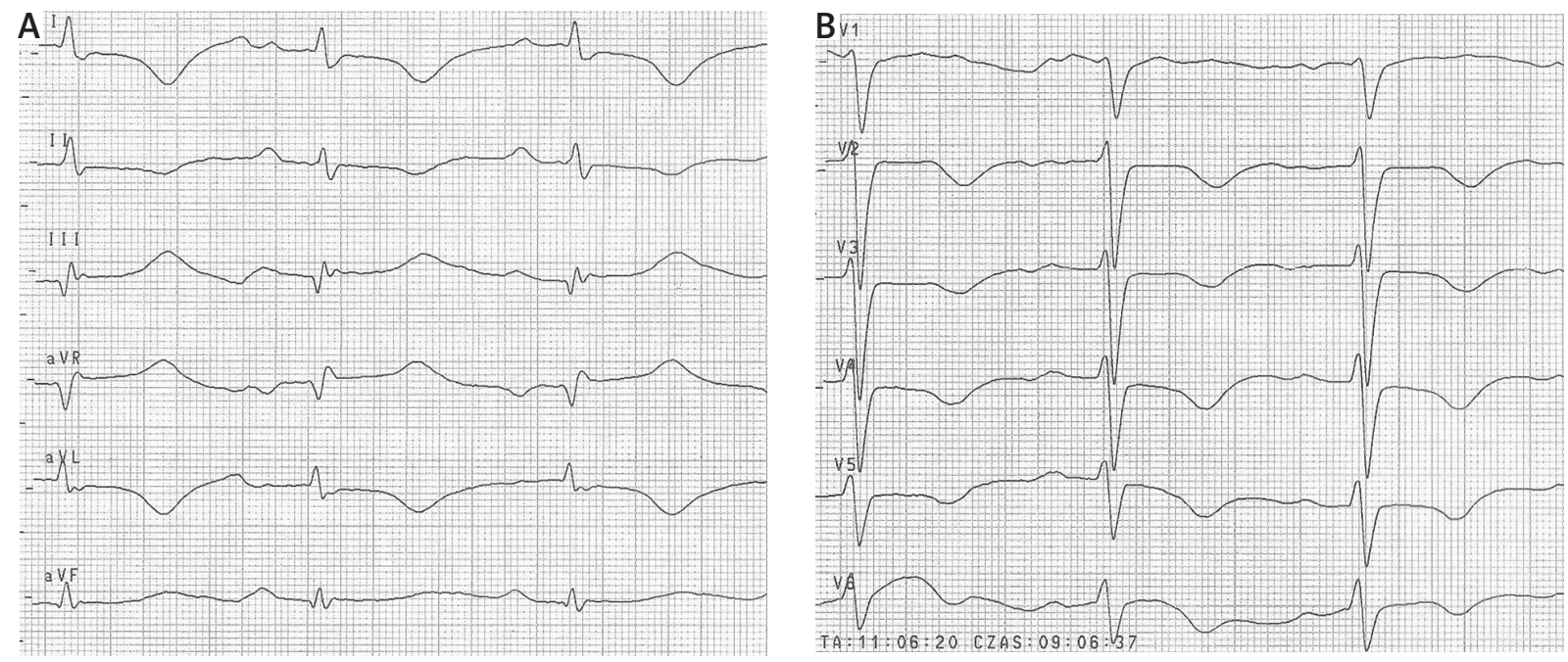

Figure 5. ECG recording on admission, $50 \mathrm{~mm} / \mathrm{s}$ (patient 2) - description in the text

The in-hospital course of the disease was not complicated. The patient was treated with ASA, ramipril, atorvastatin, and levothyroxine $12.5 \mu \mathrm{g} / \mathrm{day}$. On ECG recording on discharge deep negative $\mathrm{T}$ waves were observed. On echocardiography scan LV systolic function was significantly better, with EF $55 \%$.

Takotsubo cardiomyopathy was described for the first time in 1990, and after 14 years the Mayo Clinic identified its diagnostic criteria. To diagnose TTC all four of the following criteria must be met [6]:
- transient hypokinesis, akinesis, or dyskinesis of the LV mid segments with or without apical involvement. The wall motion abnormalities typically extend beyond a single epicardial coronary distribution (a stressful trigger is often, but not always, present),

- absence of obstructive coronary artery disease (CAD) or angiographic evidence of acute plaque rupture,

- new ECG abnormalities (ST-segment elevation and/ or T-wave inversion) or modest elevation in cardiac troponin, 
- recent head injury, intracranial bleeding, hypertrophic cardiomyopathy, pheochromocytoma, or myocarditis should be excluded.

The clinical course of TTC is similar to acute coronary syndromes and accounts for about $1 \%$ of cases of acute coronary syndromes. TTC is also called "stress cardiomyopathy" because very often its appearance is preceded by some kind of stressful agent, either physical or mental. Over $90 \%$ of patients with TTC are women during the postmenopausal period, usually aged 60-80 years, and without cardiovascular risk factors [2, 7].

"Apical ballooning syndrome" was included into the group of unclassified acquired cardiomyopathies. Its aetiology has not yet been explained. Many different theories have been proposed so far, but frequent correlation of stressful agents and TTC suggests that intensified activity of the sympathetic system and raised catecholamine concentration is the most probable. Wittstein et al. [8] reported 2-3-times higher concentration of catecholamines in patients with TTC as compared to patients with acute myocardial infarction. A case of TTC after adrenaline injection in a patient with Quincke's disease was also described [9].

Transient hypokinesis, akinesis, or dyskinesis usually concerns mid segments of the LV with apical involvement. The highest density of $\beta$-adrenergic receptors was reported in this region of the heart [10]. A toxic influence of catecholamines on myocardium was proven even earlier in other hyperadrenergic conditions like pheochromocytoma or intracranial bleeding [11, 12]. Catecholamines in high concentrations may contract epicardial coronary vessels and small vessels in coronary microcirculation and cause toxic injury of myocytes [13].

In recent years a few cases showing correlation of thyroid dysfunction with TTC have been published; for example, cases of TTC with hyperthyroidism in the course of Graves-Basedow disease, Hashimoto's disease, and cases connected with the use of levothyroxine [5].

Intensified activity of the sympathetic system caused by a sudden rise in thyroid hormones concentration and a higher sensitivity of patients with hyperthyroidism to catecholamines was postulated. A direct toxic influence of thyroid hormones on myocytes was also taken into account. None of these theories were proven, but experts recommend assessment of thyroid function in patients with TTC $[5,14,15]$.

The relationship between TTC and hypothyroidism is even less known than its connection with hyperthyroidism. The case of a 58 -year-old patient with TTC in the course of hypothyroidism complicated by dangerous ventricular rhythm disturbances was described [16]. The pathophysiology of such phenomenon has not been explained so far. On the other hand, it is certain that deficiency of thyroid hormones, mainly triiodothyronine, worsens myocardial perfusion and significantly diminishes its metabolism, increases oxidative stress, and causes direct injury of cardiomyocyte contractile elements [17]. Lee et al. [18] analysed the occurrence of low T3 syndrome in patients with TTC. In the entire population the authors found lower triiodothyronine concentrations in the acute phase of TTC as compared to the control group. As well as these findings, significantly lower concentrations of T3 in patients with bigger EF of the left ventricle $(<50 \%)$ compared to people with smaller contractile disfunction (> 50\%) were recorded.

In both discussed cases of TTC we diagnosed chronic autoimmunologic thyroid inflammation (Hashimoto's disease) with different hormone levels. In the first patient subclinical hyperthyroidism was found similarly to the patient described by Sakaki et al. [19]. In the second patient we diagnosed hypothyroidism. Hashimoto's disease is usually connected with hypothyroidism, which can be proceeded by a phase of hyperthyroidism, so it cannot be excluded that the change in hormone concentration may also influence the appearance of TTC.

The two presented cases illustrate the importance of determining thyroid hormone concentrations in patients with TTC; however, proving the correlation between TTC and thyroid diseases requires further investigations.

\section{Conflict of interest}

The authors declare no conflict of interest.

\section{References}

1. Sharkey SW, Lesser JR, Zenovich AG, Maron MS, Lindberg J, Longe TF, Maron BJ. Acute and reversible cardiomyopathy provoked by stress in women from the United States. Circulation 2005; 111: 472-479.

2. Prasad A. Apical ballooning syndrome: an important differentia diagnosis of acute myocardial infarction. Circulation 2007; 115: e56-e59.

3. Sato H, Tateishi H, Uchida T. Tako-tsubo-like left ventricular dysfunction due to multivessel coronary spasm. In: Kodama K, Haze K, Hori M (eds). Clinical aspect of myocardial injury: from ischemia to heart failure. Tokyo, Kagakuhyoronsha Publishing Co, 1990: 56-64.

4. Nef HM, Mollmann H, Elsasser A. Tako-tsubo cardiomyopathy (apical ballooning). Heart 2007; 93: 1309-1315.

5. Sarullo FM, Di Franco A, Di Monaco A, Magro S. Tako-Tsubo cardiomyopathy and thyroid dysfunction. Int J Endocrinol Metab 2011; 9: 369-372.

6. Bybee K, Kara T, Prasad A, Lerman A, Barsness GW, Wright RS, Rihal CS. Systematic review: transient left ventricular apical ballooning: a syndrome that mimics acute myocardial infarction. Ann Int Med 2004; 141: 858-865.

7. Gianni M, Dentali F, Grandi AM, Sumner G, Hiralal R, Lonn E. Apical ballooning syndrome or takotsubo cardiomyopathy: a systematic review. Eur Heart J 2006; 27 : 1523-1529. 
8. Wittstein IS, Thiemann DR, Lima JA, Baughman KL, Schulman SP, Gerstenblith G, Wu KC, Rade JJ, Bivalacqua TJ, Champion HC. Neurohumoral features of myocardial stunning due to sudden emotional stress. $\mathrm{N}$ Engl J Med 2005; 352: 539-548.

9. Zubrinich CM, Omar Farouque HM, Rochford SE, Sutherland MF. Tako-tsubo-like cardiomyopathy after EpiPen administration. Intern Med J 2008; 38: 862-865.

10. Mori H, Ishikawa S, Kojima S, Hayashi J, Watanabe $Y$, Hoffman JI, Okino $\mathrm{H}$. Increased responsiveness of left ventricular apical myocardium to adrenergic stimuli. Cardiovasc Res 1993; 27: 192-198.

11. Otsuka M, Kohno K, Itoh A. Periodic fluctuation of blood pressure and transient left ventricular apical ballooning in pheochromocytoma. Heart 2006; 92: 1837.

12. Naredi S, Lambert G, Eden E, Zäll S, Runnerstam M, Rydenhag B, Friberg P. Increased sympathetic nervous activity in patients with nontraumatic subarachnoid hemorrhage. Stroke 2000; 31: 901-906.

13. Adameova A, Abdellatif Y, Dhalla NS. Role of the excessive amounts of circulating catecholamines and glucocorticoids in stress-induced heart disease. Can J Physiol Pharmacol 2009; 87: 493-514.

14. Gerald SL. Catecholamine sensitivity, thyroid hormone and the heart: a reevaluation. Am J Med 1971; 50: 413420.

15. Pereira N, Parisi A, Dec GW, Choo J, Hajjar R, Gordon PC. Myocardial stunning in hyperthyroidism. Clin Cardiol 2000; 23: 298-300.

16. Micallef T, Gruppetta M, Cassar A, Fava S. Takotsubo cardiomyopathy and severe hypothyroidism. J Cardiovasc Med 2011; 12: 824-827.

17. Gupta Y, Ammini AC. Vitiligo, hypothyroidism and cardiomyopathy. Indian J Endocrinol Metab 2012; 16: 463465.

18. Lee SJ, Kang JG, Ryu OH, Kim CS, Ihm SH, Choi MG, Yoo HJ, Hong KS. The relationship of thyroid hormone status with myocardial function in stress cardiomyopathy. Eur J Endocrinol 2009; 160: 799-806.

19. Sakaki T, Fujioka Y, Akagami T, Masai M, Shimizu H, Sakoda T. Cardiac wall motion abnormalities observed in a patient with transient hyperthyroidism. Jpn Heart J 2004; 45: 1071-1077.

\section{Address for correspondence:}

Małgorzata Zalewska-Adamiec

Department of Invasive Cardiology

Medical University

ul. Skłodowskiej 24 A, 15-276 Bialystok, Poland

Phone: +48 858318496

E-mail: mzalewska5@wp.pl 